\title{
Numerical simulation of Urumqi Glacier No. 1 in the eastern Tianshan, central Asia from 2005 to 2070
}

\author{
DUAN KeQin $^{1 *}$, YAO TanDong ${ }^{2}$, WANG NingLian ${ }^{1} \&$ LIU HuanCai ${ }^{1}$ \\ ${ }^{1}$ State Key Laboratory of Cryosphere, Chinese Academy of Sciences, Lanzhou 730000, China; \\ ${ }^{2}$ Institute of Tibetan Plateau Research, Chinese Academy of Sciences, Beijing 100085, China
}

Received June 11, 2012; accepted July 31, 2012; published online October 12, 2012

\begin{abstract}
Due to climate changes, most of the alpine glaciers have retreated dramatically during the past decades. Thus it is significant to predict the alpine glacier variability in the future for a better understanding of the impact of climate changes on water resource. In this paper, we perform the numerical simulation on Urumqi Glacier No.1 in the eastern Tianshan, central Asia (hereafter Glacier No.1 for short) by considering both the mass balance and ice flow. Given the shape of the Glacier No.1, the velocity of the glacier is obtained by solving a two-dimensional nonlinear Stokes equation and simulated result is in agreement with the observation. In order to predict the variability of Glacier No.1 in the next decades, a climatic scenario is constructed with a temperature rise rate as $0.17^{\circ} \mathrm{C} / 10$ a and precipitation as constant during the period of 2005-2070. The simulation shows that, the glacier terminus will retreat slowly and the glacier will thin dramatically before 2040, while after year 2040, the glacier terminus retreat will accelerate. This study confirms the increasing retreat rate of alpine glaciers under global warming.
\end{abstract}

alpine glacier, numerical simulation, prediction

Citation: Duan K Q, Yao T D, Wang N L, et al. Numerical simulation of Urumch Glacier No.1 in the eastern Tianshan, central Asia from 2005 to 2070 . Chin Sci Bull, 2012, 57: 4505-4509, doi: 10.1007/s11434-012-5469-4

As the solid water reservoir, the alpine glaciers are very sensitive to climatic fluctuations. In the past decades, most of the alpine glaciers around the world have suffered from degradation, which can be considered as a direct evidence of global warming. The glacial meltwater play an important role in hydrological cycle and sea level variation [1-5]. In the arid and semi-arid regions like the northwestern China, the glacial meltwater is also an important water resource. It is estimated that glacial meltwater accounts for $22 \%$ of river runoff in the northwestern China. Some branches of the Tarim River even receive more than $40 \%$ of water from glacier runoff [6]. Thus, the prediction of the alpine glacier variability is not only of significant scientific importance, but also valuable for evaluating the water resource sustainability, especially in arid regions.

The prediction of glacier variability depends on accurate understanding of physical procedures related to glacier var-

*Corresponding author (email: kqduan@1zb.ac.cn) iation before the model establishment. The glacier variability include two parts, one is the snow or ice accumulation and ablation on the glacier surface, and the other is the ice redistribution due to the ice flow which is the key point to the glacier change simulation. When studying ice flow with years, ice can be considered as an incompressible nonNewtonian fluid that is governed by the mass and momentum conservation in the limit of a stationary nonlinear Stokes flow, in which the shear strain rate and shear stress can be described by the Green's law [7]. It was very difficult to simulate the glacier variability by solving the full Stokes equation due to insufficient understanding of glacier changes and limited calculation capability in the early years. Therefore, some studies simulated ice flow by solving simplified Stokes equation using finite difference method [8-11]. The improvement of numerical calculation capability has led to great progress in simulating ice flow, as the full Stokes equation can be solved using more advanced finite element method that enables the prediction of alpine 
glacier change $[12,13]$.

The western China holds the largest number of alpine glaciers outside the Polar Regions. Recently, continued shrinkage of these glaciers has been widely attributed to atmospheric warming according to observations on the glacier terminus and mass balance. A few studies estimated the variability of glaciers in China in the 21 st century using the statistical analysis $[14,15]$. Other studies discussed the response of alpine glaciers in China to climate change using the simplified flow models [16-19]. However, little is done in describing the numerical simulation of glacier variability based on its physical processes, thus preventing full understanding of the alpine glacier changes in China.

This paper aims to simulate the ice flow of Glacier No.1 by solving a two-dimensional Stokes equation. The coupled ice flow model with the mass balance model is then used to predict the variation of Glacier No.1 in a climate scenario for the next decades.

\section{Method and data}

Due to gravity, glacier flows downslope, with its velocity mainly controlled by the shape of the glacier. Snowfall exceeds snow melt (accumulation) in the upper reach of the glacier, while ice melt dominates in the lower reach of the glacier (ablation). This results in changes of the glacier shape, which, in return, leads to variation of ice velocity. As shown in Figure 1, glacier in the accumulation zone flows down to compensate the melting ice in the ablation zone. When the loss of ice in the ablation zone surpasses its gain from the accumulation zone, the glacier will retreat and vice versa. Thus, to acquire a holistic picture of the variability of a glacier, both the mass balance and ice flow velocity should be considered.

From the mass conservation perspective, the vertically integrated continuity equation, describing how the change in ice thickness $H$ is related to flux divergence and specific mass balance $b$, can be written as

$$
\frac{\partial H}{\partial t}=b-\nabla \cdot(\vec{V} H) .
$$

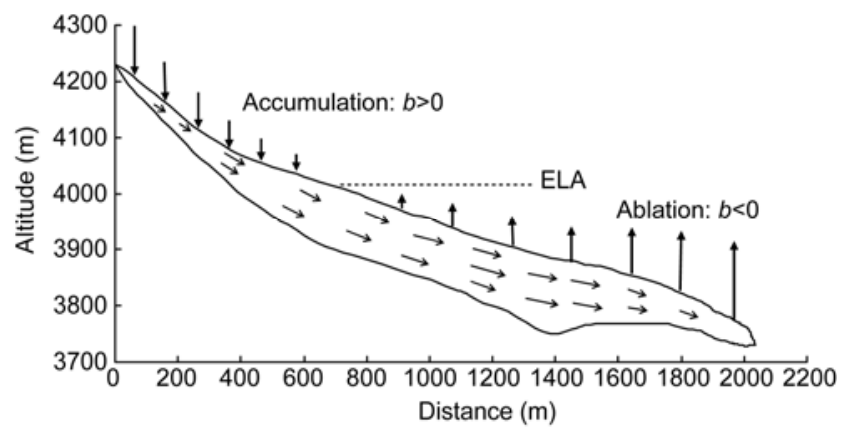

Figure 1 Sketch map of accumulation, ablation and ice flow in Glacier No.1. ELA means equilibrium line altitude.
The variable $\vec{V}$ in eq. (1) is the velocity at the time $t$. This equation means the variation of the thickness of a glacier depends on both the mass balance and ice flow flux divergence.

\subsection{Ice flow equation}

Glacier ice is generally treated as an incompressible, heatconducting non-Newtonian fluid. Then glacier flow can be described by the Stokes equation:

$$
\begin{gathered}
\rho \frac{\mathrm{d} \bar{V}}{\mathrm{~d} t}=\nabla \cdot(2 \eta \vec{D}-p \vec{I})-\rho \vec{g}, \\
\nabla \cdot \vec{V}=0,
\end{gathered}
$$

where $p$ is the pressure. $\vec{I}$ is the identity stress tensor. $\vec{D}=\frac{1}{2}\left(\nabla \vec{V}+\nabla \vec{V}^{T}\right)$ is the train rate tensor. $\eta=\frac{1}{2} A^{-\frac{1}{n}}$ $(\sqrt{0.5 \times(\vec{D} \cdot \vec{D})})^{\frac{1-n}{n}}$ is the viscosity coefficient, whereby $n$ is the flow index and can be taken as 3 , and $A$ is the flow parameter related to glacial temperature. In this paper, $A$ equals to $2.22 \times 10^{-24} \mathrm{~Pa}^{-n} \mathrm{~s}^{-1}$.

\subsection{Mass balance equation}

Mass balance is the algebraic sum of accumulation and ablation on the glacial surface. As shown in Figure 1, when accumulation is larger than ablation, mass balance is positive and vice versa. There are two types of mass balance models, one is the statistical degree-day model and the other is the energy-mass balance model which describes the energy balance process at the glacial surface. However, the parameters of energy-mass balance model are difficult to obtain on the alpine glaciers, thus confining the application of the model to most glaciers on high altitudes. In contrast, the parameters of the degree-day mass balance model are easy to get and bear definite physical meanings. That may be why the degree-day mass balance model has been so widely applied to the alpine glaciers in the mass balance simulation $[20,21]$. The general degree-day mass balance model is shown as:

$$
\begin{gathered}
b=\int_{t}\left[(1-f) \cdot m+P_{\mathrm{s}}\right] \mathrm{d} t, \\
m=\mathrm{DDF} \times \mathrm{PDD}=\mathrm{DDF} \times \sum_{i=1}^{n} H_{\mathrm{t}} \cdot T_{\mathrm{t}},
\end{gathered}
$$

where $f$ is the refrozen ratio taken to be $0.1 . m$ is the water equivalent of melting ice, which is the product of degree-day factor (DDF) and positive accumulated temperature (PDD) during a certain period. $T_{\mathrm{t}}$ is the daily mean temperature. $H_{\mathrm{t}}$ is the logical variable. When $T_{\mathrm{t}} \geqslant 0, H_{\mathrm{t}}=1$ 
and when $T_{\mathrm{t}}<0, H_{\mathrm{t}}=0 . P_{\mathrm{s}}$ is the solid precipitation at a certain altitude of a glacier, and can be computed by [22]:

$$
P_{\mathrm{s}}= \begin{cases}P & T<T_{\mathrm{s}}, \\ \frac{T_{1}-T}{T_{1}-T_{\mathrm{s}}} P & T_{\mathrm{s}} \leqslant T \leqslant T_{1}, \\ 0 & T>T_{1},\end{cases}
$$

where $P$ is the precipitation total at a certain altitude, $T_{\mathrm{s}}$ and $T_{1}$ are the critical temperature of solid and liquid precipitation, and equal to $0^{\circ} \mathrm{C}$ and $2^{\circ} \mathrm{C}$, respectively.

\subsection{Data}

When it comes to numerical modeling of a glacier, parameters such as degree-day factor, precipitation, temperature and glacial shape are essential for eqs. (1)-(6). However, most observations on glacier variability in the western China are focused on mass balance and the terminus, and are temporally inconsistent. Fortunately, there are few glaciers such as Glacier No.1 that have been systematically monitored since the 1960s. The observation results [18,19,23-27] can meet the demand for the numerical simulation. For example, the variation of degree-day factor with altitudes has been studied by Cui et al. [24] and the shape of the glacier has been surveyed by Li et al. [19].

Air temperature and precipitation amount along the slope of Glacier No.1 is derived from the data at Daxigou meteorological station, taken the temperature and precipitation gradient with altitudes as $-0.6^{\circ} \mathrm{C} / 100 \mathrm{~m}$ and $22 \mathrm{~mm} / 100 \mathrm{~m}$ [28], respectively. The station (3539 $\mathrm{m}$ a.s.1.) is $2.5 \mathrm{~km}$ away from the glacier.

To predict the change of Glacier No.1, a climate scenario is assumed in reference to the warming rate during 1959 to 2004 recorded at Daxigou meteorological station, i.e., temperature increases at a linear trend of $0.17^{\circ} \mathrm{C} / 10$ a during 2005-2070. The assumed temperature linear trend is consistent with the B1 scenario provided by IPCC [3]. There is no significant variation trend of precipitation amount at Daxigou from 1959 to 2004, the precipitation in the Glacier No.1 area is therefore assumed to be constant in the next decades.

\section{Numerical simulation of ice flow}

In order to simulate the ice flow of Glacier No.1, we need to solve eqs. (2) and (3). Observation shows that the annual mean ice flow velocity of Glacier No.1 is less than $8 \mathrm{~m} / \mathrm{a}$, which means $\rho \frac{\mathrm{d} \bar{V}}{\mathrm{~d} t}$ in eq. (2) can be ignored compared to the other two items. Then, eq. (2) is simplified into stress equilibrium equation. The pressure at the glacial surface equals to that in the atmosphere. The bottom of the glacier could be frozen, thus the bed rock can be taken as a fixed boundary, which means the velocity at the bottom of the glacier $\left(V_{\mathrm{b}}\right)$ is 0 . On the other hand, the bottom layer of the glacier may slide along the bed rock in the function of $v(x, t)$. Therefore, the boundary conditions of eqs. (2) and (3) are expressed as

$$
\begin{aligned}
& \text { At the surface: }(-p \vec{I}+2 \eta \vec{D}) \cdot \vec{n}=p_{\text {air }} \cdot \vec{n} \text {, } \\
& \text { At the bottom: } V_{\mathrm{b}}=v(x, t),
\end{aligned}
$$

where $p_{\text {air }}$ is the air pressure, $\vec{n}$ is the outward unit vector.

It is very difficult and currently unable to solve the nonlinear equations (2) and (3) in three dimensions due to the complication of numerical simulation and lack of the initial and boundary conditions. Therefore, in this paper we only try to solve eqs. (2) and (3) in two dimensions at the vertical profile along the main streamline of the glacier in Figure 2.

Figure 2(a) is the triangular mesh deformation of the vertical profile with refinement meshes in the lower reach of the glacier considering its complicated variation. There are 4919 meshes totally. Our study shows that in the lower reach of the glacier, movement at the glacier bottom, with the average velocity as around $2.5 \mathrm{~m} / \mathrm{a}$, accounts for about $50 \%$ of the entire glacier flow [18]. Glacier flow at the bottom is therefore essential in the consideration. Figure 2(b) shows the velocity field by solving eqs. (2) and (3) and (7) and (8). Figure 3 compares the simulated surface flow velocity in Figure 2(b) with the observation, demonstrating a good agreement between the two. We therefore conclude that it is feasible to simulate the glacier flow based on the Stokes equation.

\section{Numerical simulation of future variation of Glacier No.1}

To numerically simulate future variation of Glacier No.1, we integrate eqs. (1)-(8), and practice the following technological process in the simulation (Figure 4).

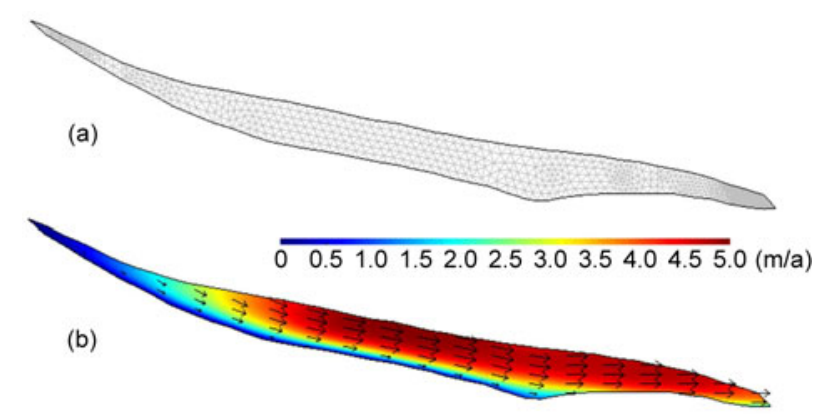

Figure 2 The triangular mesh deformation in the vertical profile of Glacier No.1 (a) and the simulated velocity field (b). 


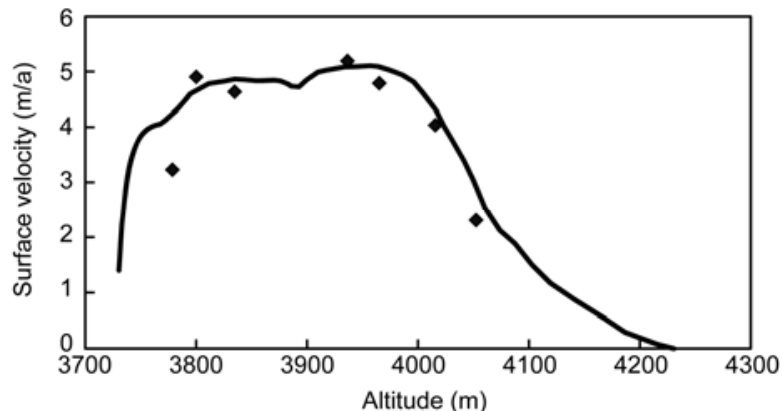

Figure 3 Comparison of the simulated (line) and observed (dot) surface velocity.

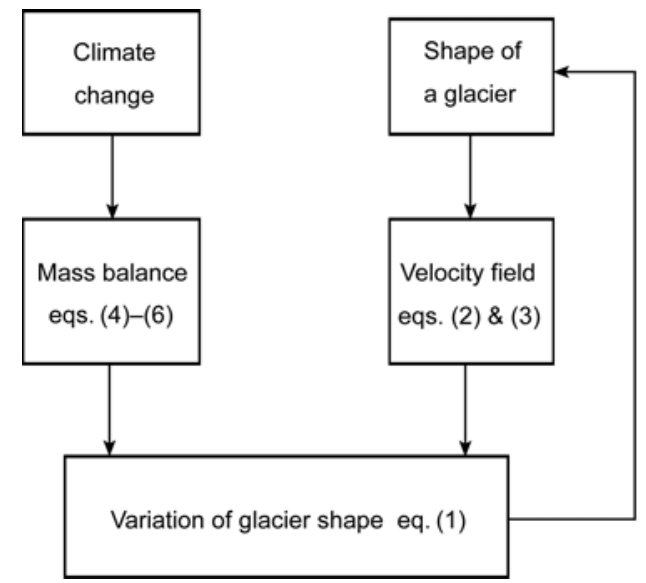

Figure 4 Thie simulation process to integrated eqs. (1)-(8) for the Glacier variability.

The variations of Glacier No.1 during 2005-2070 are simulated under the climate scenario constructed in section 1.3. The glacier variation with time is shown in Figure 5. Before 2040, the glacier would retreat rather gently but with a rapid thinning rate in the lower reach of the glacier, while after 2040 glacier retreat would accelerate with continuous thinning. The simulation indicates the glacier retreat as $\sim 290 \mathrm{~m}$ during 2005-2040, with the rate increasing to $\sim 950$ $\mathrm{m}$ during 2040-2070. By the Year 2070, ice will have melted away below $4000 \mathrm{~m}$ a.s.l., leaving the remaining part

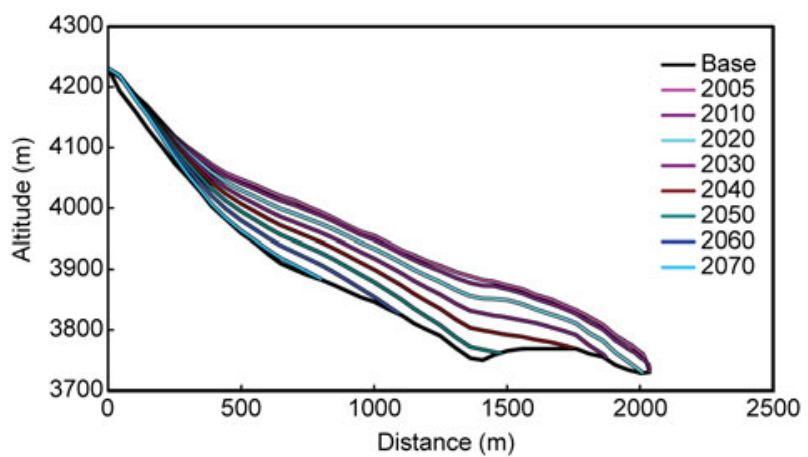

Figure 5 Variation of the Glacier No.1 with time under a reconstructed climatic scenario. of the glacier above $4000 \mathrm{~m}$ a.s.l as a cirque glacier.

\section{Discussion and conclusions}

The variations of a glacier include two parts according to eq. (1), one is the mass balance on the glacial surface, and the other is the ice convergence and divergence due to ice flow. The mass balance can be measured directly by the stakes on the glacier surface. However, the convergence and divergence occurring in the glacier interior can only be obtained through calculation. Let $\Delta h=-\nabla \cdot(\vec{V} H)$ in eq. (1), then $\Delta h$ is the elevation variation of the glacier surface with the convergence and divergence. When $\Delta h$ is positive, it means that the elevation of the glacier surface increases due to the convergence and vice versa. Figure 6 shows the comparison between the calculated $\Delta h$ and the measured mass balance $b$ with altitudes in 2005, demonstrating identical values of $\Delta h$ with $b$. This means that the loss of ice in the ablation zone could be compensated through ice flow by the mass gain in the accumulation zone. Specifically, $\Delta h$ is negative and $b$ is positive above $4000 \mathrm{~m}$ a.s.l., indicating positive mass balance increases the glacial surface elevation while mass divergence due to ice flow decreases the elevation. Below $4000 \mathrm{~m}$ a.s.l., on the other hand, $\Delta h$ is positive and $b$ is negative, indicating negative mass balance decreases the glacial surface elevation while mass convergence due to ice flow increases the elevation. The shape of a glacier is therefore constantly changing.

The flow velocity of Glacier No.1 decreased during 1981-2007 [26]. According to the numerical simulation, with the thinning and retreat of Glacier No.1, the flow velocity would have decreased during 2005-2070, resulting in less ice transportation from the accumulation zone to the ablation zone. As shown in Figure 5, due to the thick ice layer and fast flow in 2005, the strong downward transportation of ice compensate for the loss of ice in the ablation zone, leading to slow glacier retreat before Year 2040. Although the recession of terminus is slow, the supplement from upper reach of the glacier is smaller than the mass

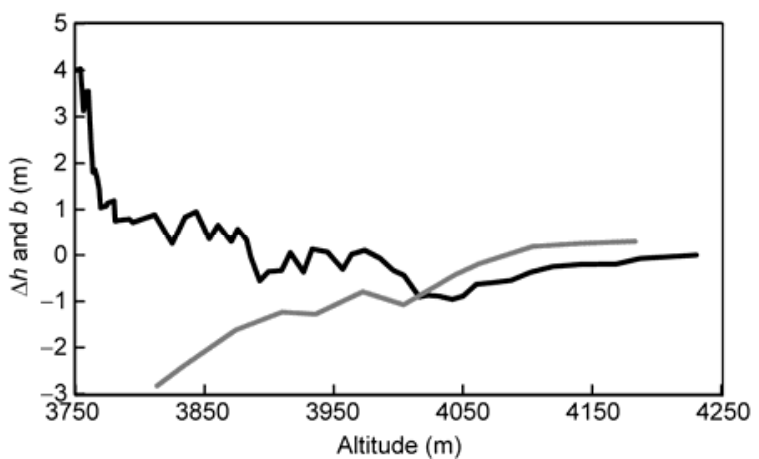

Figure 6 Comparison of the mass balance (gray line) and $\Delta h$ (black line) with altitudes in 2005 . 
balance, resulting in rapid thinning of the glacier. After Year 2040, ice flow velocity decreases with thinning glacier and decreasing accumulation coverage, leading to further thinning of the glacier in the ablation zone and accelerated glacier terminus recession, as the mass gain in the accumulation zone fails to supplement timely the loss in the ablation zone. Thus if the global warming continues, the alpine glaciers' retreat will become a more and more serious issue.

In summary, to comprehensively study and predict the alpine glacier variability and its response to climate change, both mass balance and ice flow should be considered. The development of numerical computation skills and software enables the solution of the Stokes equation. Although viscosity coefficient is a function of temperature, it is set to be constant regardless of the variation of glacier temperature in this simulation. Glacier is a three-dimensional fluid. So the velocity field of the two-dimensional simulation cannot reflect the actual movement. Besides, the velocity field is determined by the movement of the glacial bottom to a large extent. However, it is still unclear how the sliding velocity at the glacial bottom changes with increasing glacier temperature. Further study and observation are therefore needed. Future work should be focused on the solution of the three-dimensional Stokes equation coupled with Heat Transfer equation and the Mass Balance model in order to better simulate the glacier change and its response to climate change.

We are grateful to the editor and anonymous reviews for their critical and helpful comments. This work was supported by the National Natural Science Foundation of China (41190080, 40971290 and 40771209) and the National Basic Research Program of China (2010CB951703).

1 Yao T D, Wang Y Q, Liu S Y, et al. Recent glacial retreat in High Asia in China and its impact on water resource in Northwest China. Sci China Ser D-Earth Sci, 2004, 47: 1065-1075

2 Yao T D. Glacial fluctuations and its impacts on lakes in the southern Tibetan Plateau. Chin Sci Bull, 2010, 55: 2071

3 Yao T D, Thompson L, Yang W, et al. Different glacier status with atmospheric circulation in Tibetan Plateau and surroundings. Nat Clim Change, 2012, doi: 10.1038/NCLIMATE1580

4 Li K M, Li Z Q, Gao W Y, et al. Recent glacial retreat and its effect on water resources in eastern Xinjiang. Chin Sci Bull, 2011, 56: 3596-3604

5 Ren J W, Ye B S, Ding Y J, et al. Initial estimate of the contribution of cryospheric change in China to sea level rise. Chin Sci Bull, 2011, 56: $1661-1664$

6 Yang Z N. Glacier Water Resourses in China (in Chinese). Lanzhou: Gansu Science and Technology Press, 1991. 158

7 Glen J W. The creep of polycrystalline ice. Proc R Soc A, 1995, 228: 519-538

8 Nye J F. The frequency response of glacier. J Glaciol, 1965, 5: 567-587

9 Oerlemans J. A model of the Antarctic ice sheet. Nature, 1982, 297: $550-553$
10 Martina S, Emmanuel L M. Improvement of a 2-D SIA ice-flow model: Application to glacier de Saint-Sorlin, France. J Glaciol, 2007, 53: 713-722

11 Picasso M, Rappaz J, Reist A, et al. Numerical simulation of the motion of a two dimensional glacier. Int J Numer Meth Engng, 2000, 00: $1-6$

12 Jouvet G, Pinasso M, Rappaz J, et al. A new algorithm to simulate the dynamics of a glacier: Theory and applications. J Glaciol, 2008, 54: $801-811$

13 Guillaume J, Huss $\mathrm{M}$, Blatter $\mathrm{H}$, et al. Numerical simulation of Rhonegletscher from 1874 to 2100. J Comput Phys, 2009, 228: 6426-6439

14 Shi Y F, Liu S Y. Estimation on the response of glaciers in China to the global warming in the 21st century. Chin Sci Bull, 2000, 45: $668-672$

15 Xie Z C, Wang X, Feng Q H, et al. Modeling the response of glacier systems to climate warming in China. Ann Glaciol, 2006, 43: 313316

16 Wang W T, Liu Z X. Analysis of the frequency response behaviour of the Glacier No.1 at the Urumqi River headwaters, Tianshan (in Chinese). J Glaciol Geocryol, 1984, 6: 13-24

17 Cao M S, Meier M F. Calculation of glacial longitudinal sections under stable conditions-Glacier No.1 at the headwater of the Urumqi River, Tianshan Mt. as an example (in Chinese). J Glaciol Geocryol, 1987, 9: 131-138

18 Zhou Z M, Li Z Q, Li H L, et al. The Flow Velocity features and dynamic simulation of Glacier No.1 at the headwater of the Urumqi River, Tianshan Mountains (in Chinese). J Glaciol Geocryol, 2009, 31: 55-61

19 Li H L, Felix N G, Li Z Q, et al. An extended "perfect-plasticity" method for estimatingice thickness along the flow line of mountain glaciers. J Geophys Res, 2012, 117: F01020

20 Zhang Y, Liu S Y, Han H D, et al. Spatial variation of degree-day factors on the observed glaciers in western China (in Chinese). J Glaciol Geocryol, 2006, 61: 89-98

21 Wang S, Pu J C, Wang N L. Study of the mass balance and sensibility to climate change of the Qiyi glacier in the Qilian Mountains (in Chinese). J Glaciol Geocryol, 2011, 33: 1214-1221

22 Kang E S, Cheng G D, Lan Y C, et al. A model for simulationg the response of runoff from the mountainous watersheds of inland river basins in the arid area of northwest Chiina to climate change. Sci China Ser D-Earth Sci, 1999, 29 (Suppl): 52-63

23 Yang H A, Li Z Q, Ye B S, et al. Study on mass balance and process of Glacier No.1 at the headwaters of the Urumqi River in the past 44 years (in Chinese). Arid Land Geogr, 2005, 28: 76-80

24 Cui Y H, Ye B S, Wang J, et al. Analysis of the spatial-temporal variations of the positive degree-day factors on the Glacier No.1 at the headwaters of the Urumqi River (in Chinese). J Glaciol Geocryol, 2011, 32: 265-274

25 Jiao K Q, Ye B S, Han T D, et al. Response of runoff to climate change in the Glacier No.1 at the Urumqi River headwaters, Tianshan Mountains during 1980-2006 (in Chinese). J Glaciol Geocryol, 2011, 33: 606-611

26 Zhou Z M, Jing Z F, Zhao S H, et al. The response of glacier velocity to climate change: A case study of Urumqi Glacier No.1 (in Chinese). Acta Geosci Sin, 2010, 31: 237-244

27 Li Z Q, Shen Y P, Wang F T, et al. Response of glacier melting to climate change-Take Urumqi Glacier No.1 as an example (in Chinese). J Glaciol Geocryol, 2007, 29: 333-342

28 Yang D Q, Jiang T, Zhang Y S, et al. Analysis and correction of errors in precipitation measurement at the head of Urumqi River, Tianshan (in Chinese). J Glaciol Geocryol, 1988, 10: 384-400

Open Access This article is distributed under the terms of the Creative Commons Attribution License which permits any use, distribution, and reproduction in any medium, provided the original author(s) and source are credited. 